شخصية|لعدد 


\section{الدكتورعبدالفزيزالشناوى كماعرفته}

$$
\text { د/ السعيد رزق حجاج }
$$

أستاذ التاريخ الحديث ـ جامعة الأزهر

عميد كلية الدراسـات الإنسانية للبنات 


\section{اللدكتور عبدالعزيز الشناوى كها عرقفته}

عندمـا شـرفتى سعـادة الأسـتاذ الدكتور رئيس تحـرير مجـلة "مصـر الحـديثة التى تعتبر أفضل المجالات التى صدرت فى السنوات الأخيرة باختيارى للكتابة عن شخحسية العـدد، المؤرخ العبقـرى الدكتور عبـد العزيز الشنـاوى الذى شـرفت بأن أكون واحداً همن تتلمذوا على يديه وعلى الرغم من سعادتى الغامرة بالكتابة عنه اله إلا أن حيـرتى قد ازدادت لأسسباب عديدة أهمها ضيق الوقت وتسـارع الأحداث فى

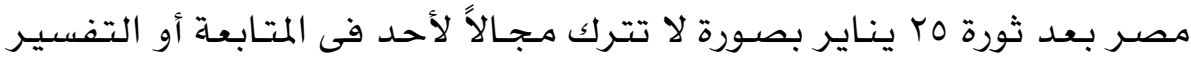
والتحليل والأهـم أن الدكتور الشنـاوى يصعب تناول شخصسيته فى مقالة سـريعة كهذه من هـنـا كـان القـرار وهـو أن تكون خواطر متضـمنـة الحـديث عن الشـنـاوى الإنسـان قبل المؤرخ كما عرفته راجياً أن تتاح لى فرصسة مناسسبة للكتابة عنه وعن منهجه التاريخى ومؤلفاته فى عمل كبير يليق بهكانته كثيخ للمؤرخين المعاصرين.

ولد رحمها الله فى الـدقهليـة لأب يعهل بـالتجـارة وأم من أسـرة معـروفة فى مـدينـة أجـا، وكان الابن الأكبر لثلاثة من الأشقاء هم أحمد وأنور وفتحى وشقيقة وحيدة هى زينب. وبدأ دراسته فى الكتاب المجاور لمنزله بالإسكندرية وحفظ القرآن الكريم وهو مـا أثر كثيـرا فى تمـكنه من اللغـة العربيـة ثم التحق بـالمدرسـة الابتدائية فى رأس التين وتابع دراستاه بهـدرسـة العباسيـة الثانوية وحصل على التوجيهية عام • 194 ليلتحق بكليـة الآداب بالجـاهعـة المصريـة (القـاهـرة) وتخرج فى قسـم التاريخ عام عساوا وفى نفس العام التحق بهعهد التربيـة العالى ليحصل على دبلوم المعهد عام

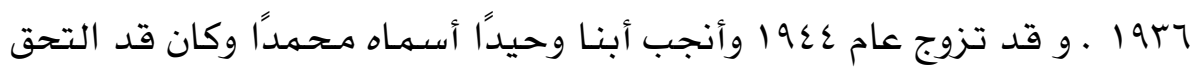
بسلك القضاء حتى تولى منصب نائب رئيس محكمة النقض، 


\section{حياته العملية:}

بدأ حياته العمليـة مـدرساً بالتعليهم الثانوى بهـدرسة السويس عام 1947 ا، ثم

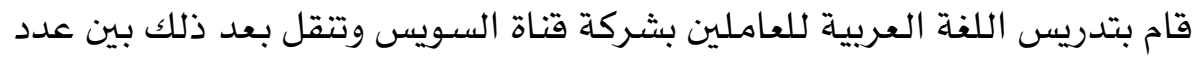

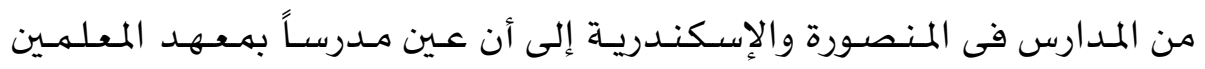

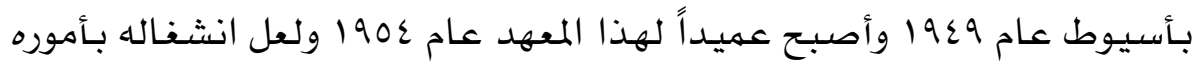

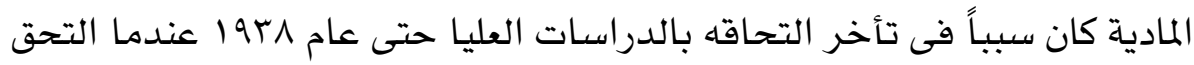

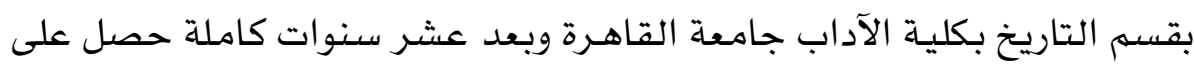

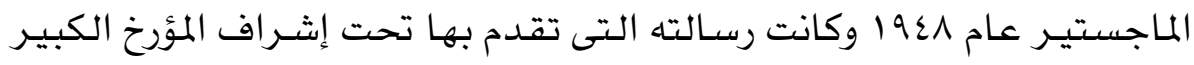

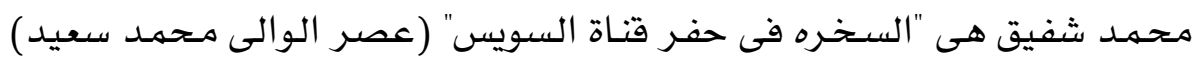

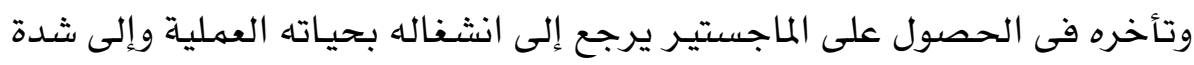

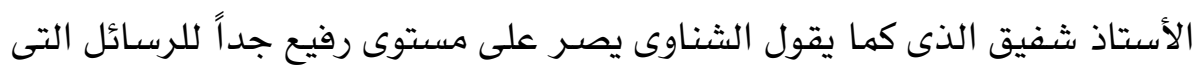

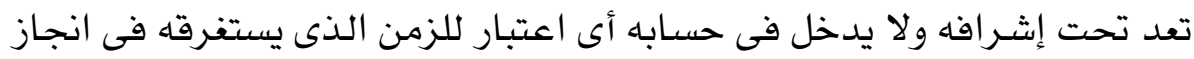
البحث.

ويقول الدكتور الشنـاوى فى مقدمـة كتاب السخرة "لا أنكر أن الشدة العلمية

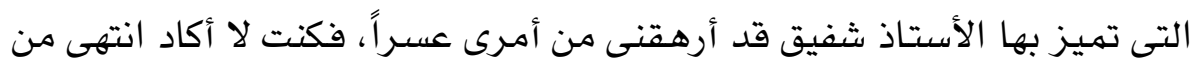

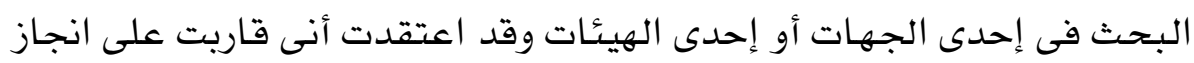

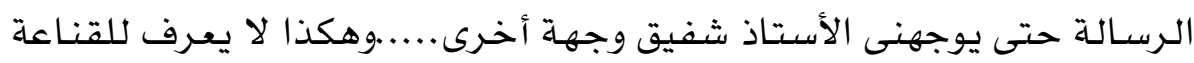

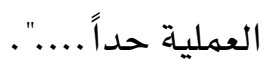

وقد حصل الشناوى على الدكتوراه من كليـة الآداب جامعـة الإسـكندريـة عام

190r عن موضوع "السخرة في حفر قناة السويس (عصر إسماعيل)" . وبدأت حياة الدكتور الشناوى بعد الدكتوراه تأخذ مساراً آخر حين انتهى به الهـ

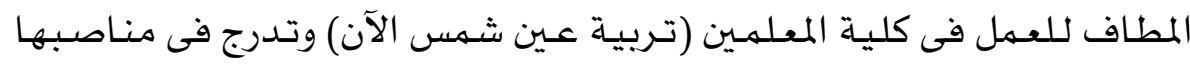

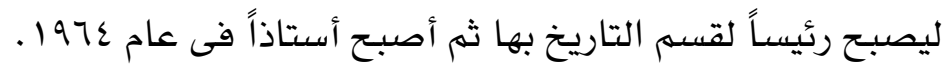

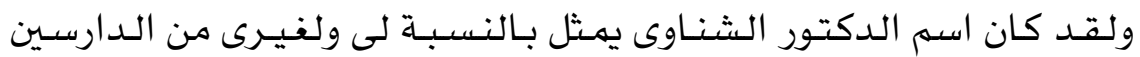


للتـاريخ حلماً بعيد المنـال قرأت له بعض مؤلفـاته وأنا فى المرحلة الثانوية ولم أتصور يوماً أن أكون واحداً من تلامذتاله والقريبين منهـ.

يهكن القول دون تحفظ أن الدكتور الشناوى مـن أبرز المؤرخين الذى جهعوا

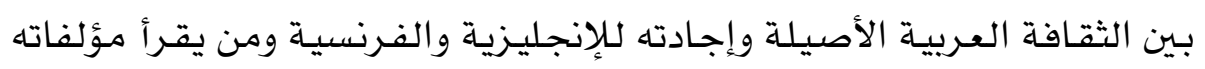
العديدة يتأكد من ذلك تماماً. عرفتـاه نحن تلامذته بـدماثة الخلق وكريم الصفات والشجاعة الأدبية النادرة

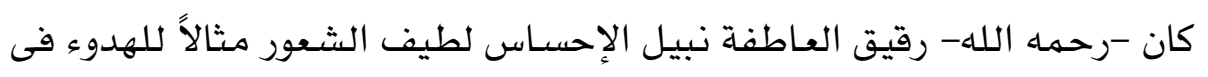
اباء وسكينة لكنه عندما يغضب للحق تراه بركانا هـادراً.

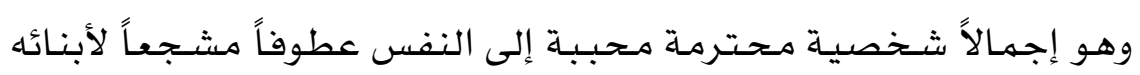

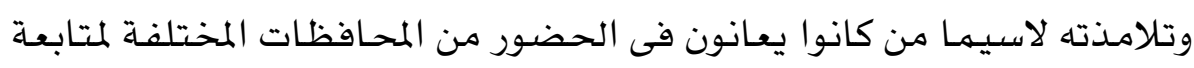
محساضراته فى الدراسات العليا، وكما تقول شقيقته زينب الشناوى كان مضان مضيافاً

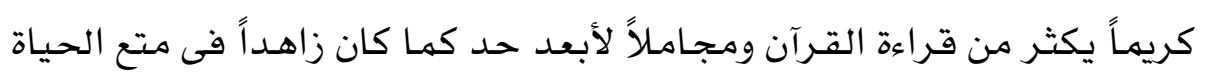

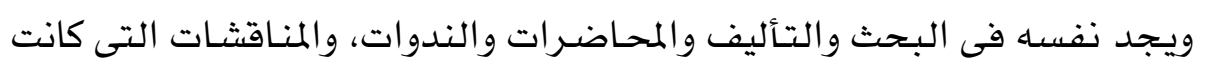

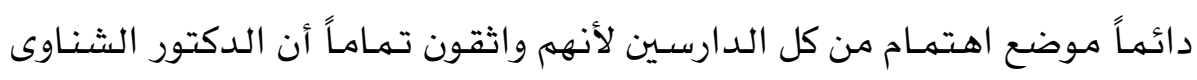

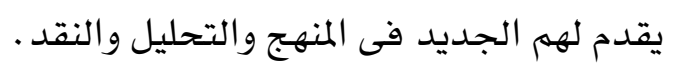
كتب عن الأزهـر والأزهـريـين مالم يكتبه أحد منهم ويكفى مطالعة موسـوعة

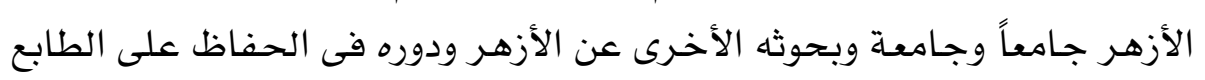
العربى لمصر وأروقة الأزهر.

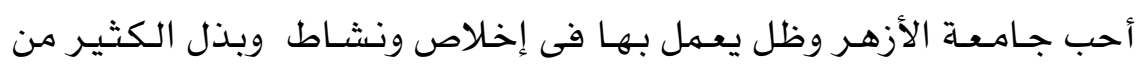
الجهد وتعرض للكثير من المضايقات من بعض الحاقدين ومن كان في نفوسهيه

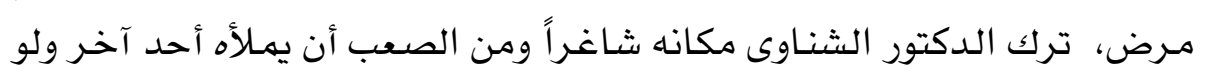

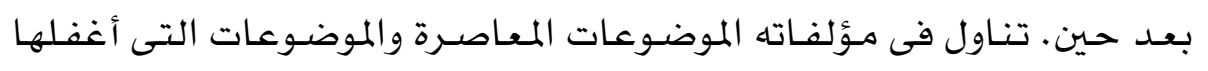

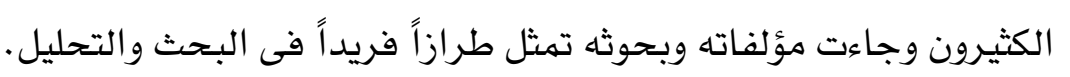


وعلى الرغم من عبقريته كمؤرخ وشهرته بين جميع الباحثين لكنه كان عزوفاً عن المناصب والأضواء فلم يسع إلى صحيفـة يكتب فيها أو وسيلة إعلانية يظهر

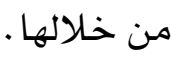

ويفسر البعض ذلك باعتزازه الكبير بنفسه وجرأته في قول الحق ومعارضته للاستبداد وكرهـ الشديد للنفاق والتملق.

كان مثالاً فى الانضباط لا يقبل اعتذاراً عن موعد أو تهاوناً فى عمل يكلف

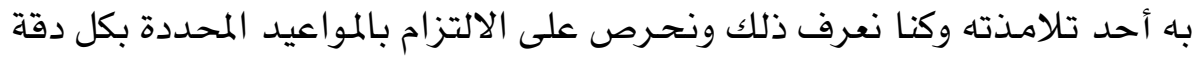
نسارع فى إنجاز ما يكلفنا به بهنتهى الدقة والجدية وإلا .... تعرفت على الدكتور الشنـاوى وأنا فى المرحلة الثانوية من خلال قراءة كتابه

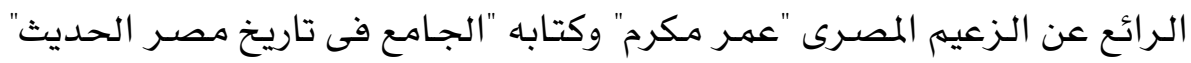
وكذلك كتابه "السخرة فى حفر قناة السويس" وانبهرت بأسلوبه ومنهجها وقلت من من الصعب أن أجلس إلى أسـاذ بهذه الروعة ولعل بيت الشعر الذى كتبه الشـاعر

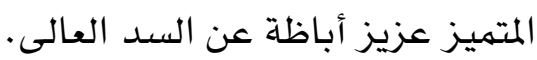

كان حلماً فخاطراً فاحتمالاً ثم أضحى حقيقة لا خيالا

هـا البيت يعبر تماماً عن علاقتى بـأستاذى الدكتور الشنـاوى فبعد انتهاء المرحلة الثانوية والالتحاق بقسم التاريخ بكلية اللغة العربية - جامعة الأزهر بدأنا ندرس بعض مؤلفاته وفى مقدمتها كتابه البديع "أوربا فى مطلع العصور الحديثة لهيه"

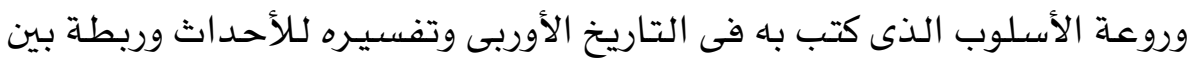
التاريخ الأوربى والتاريخ العربى.

ومرت سنوات الدراسة ولهم نلتق بالدكتور الشناوى لكننا ندرس مؤلفاته ونقراً بحوثه ونسهع عنه من تلامذته الذين سبقونا إلى أن كانت مرحلة الدراسـات العليا

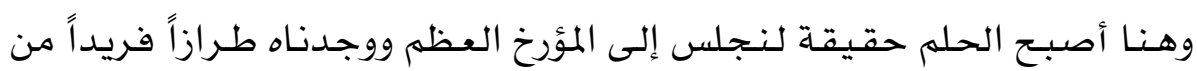

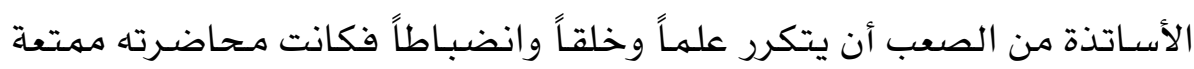


شيقة مليئة بكل جديد تمر الساعات الثلات وكأنها لحظات تتقطع أنفاسنا ونحن

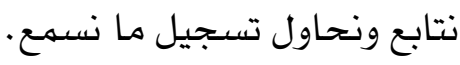

كان يـحاضرنا فى كل شىء فى تاريخ مصر الحديث وفى التاريخ الأوربى، فى

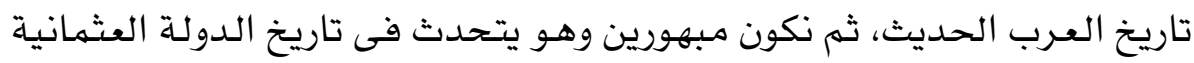

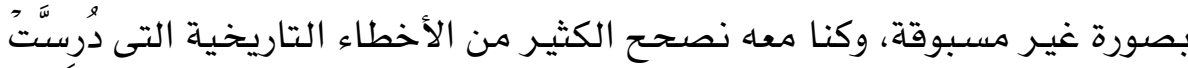

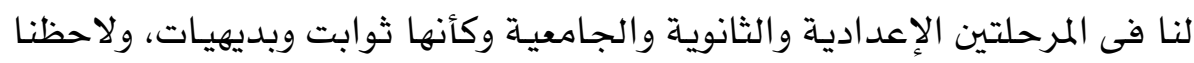

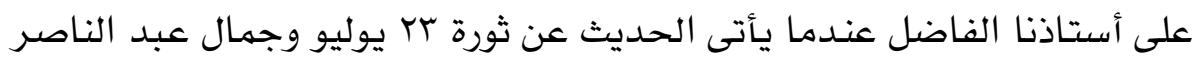

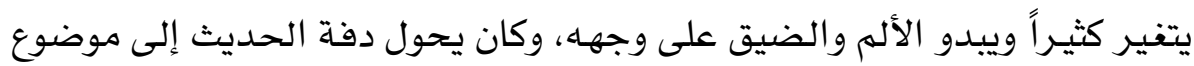

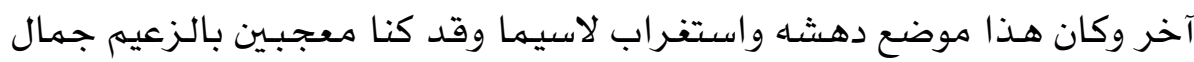

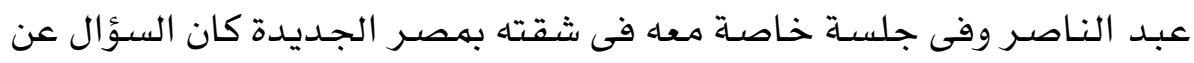

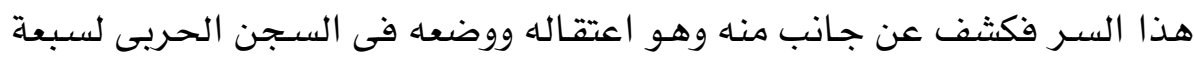

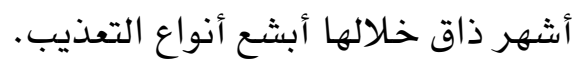

والدكتور الشنـاوى بكل تأكيد ينتمى إلى جيل العهمالقة من المؤرخين الذين

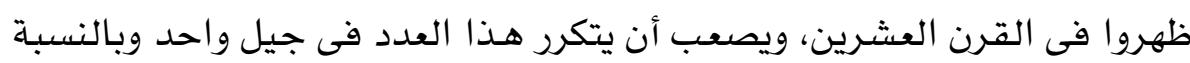

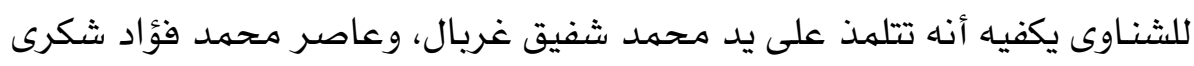

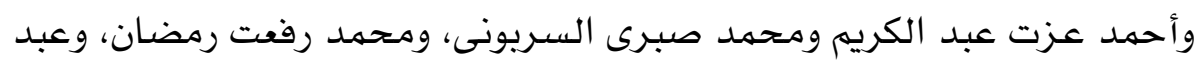

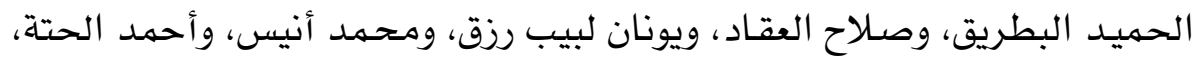

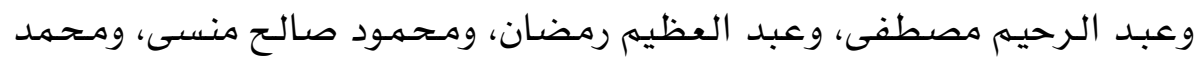

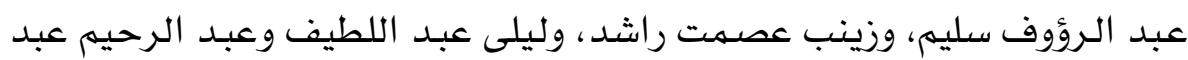
الرحهن وغيرهم كثيرون.

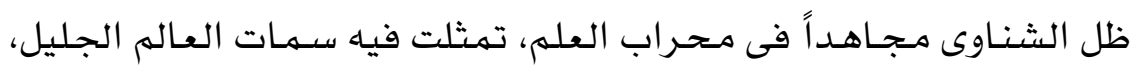

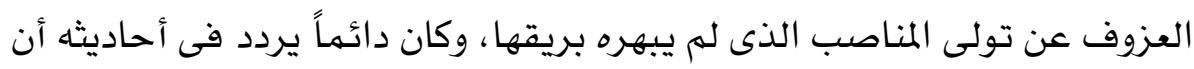
المجد العلهى هو قمة الأمجاد لأنه مجد لا يبلى، بل هو مجد يلمد يعادل الزمن وجوداً. 


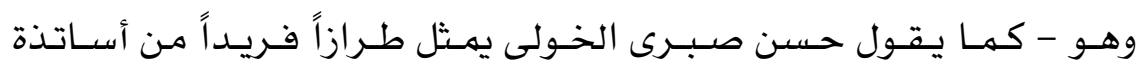

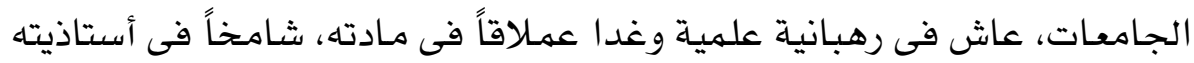

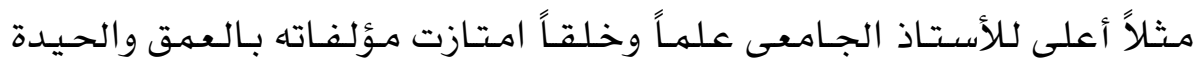
والشهمول فأثرى الفكر العربى بألوان من الدراسـات التاريـخيـة الجذابة عـرضهاً فى أسلوب ناصع مشرق وعلى نحو علمى دقيق. وهو أشبـه بـالشــرة الطيبـة المثقـلة بـالثمـار تعطى ولا تشعـر أنها أعطت

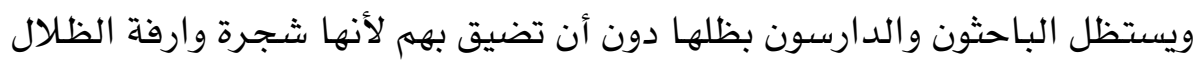

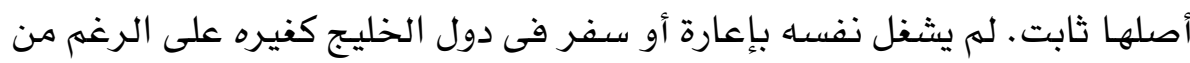

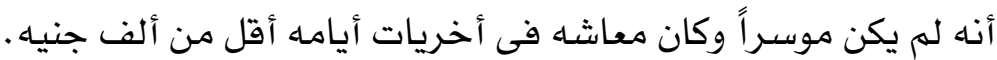
شـرفت بأن أكون أحد تلامذته فى الدراسـات العليا وكلفنى بكتابة بحث عن

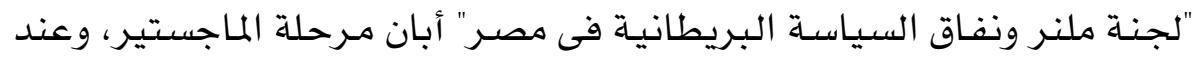

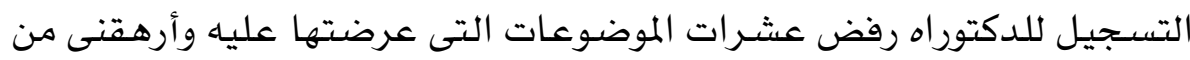

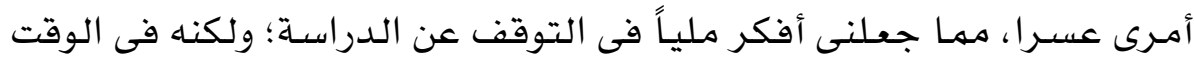

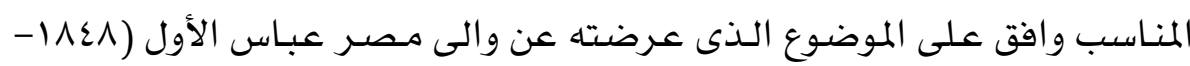

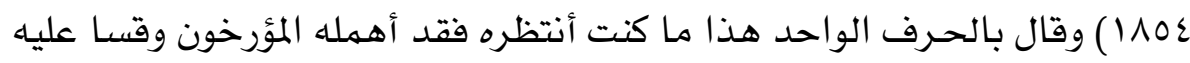

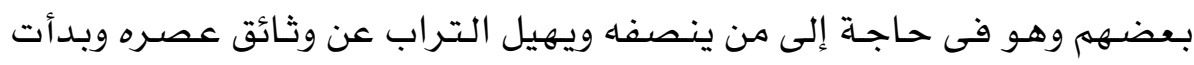

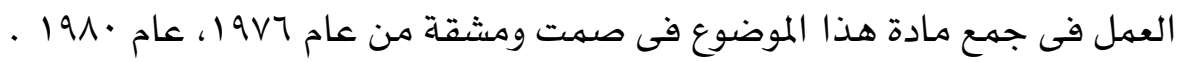
ولا أنسى مـا حييت يوم المناقشـة حين أمسك بـالرسـالة وهو يقول:" للتاريخ

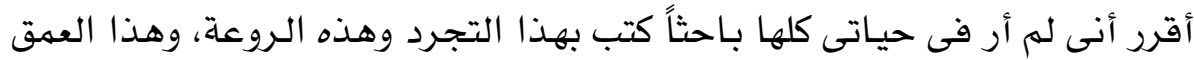

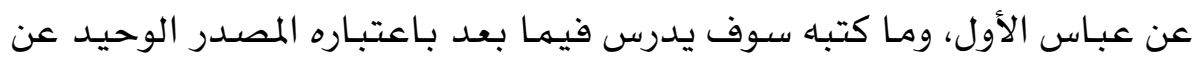

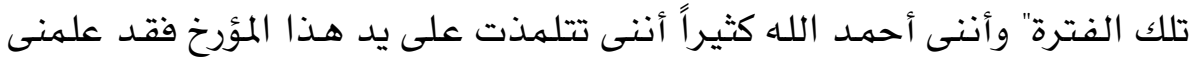

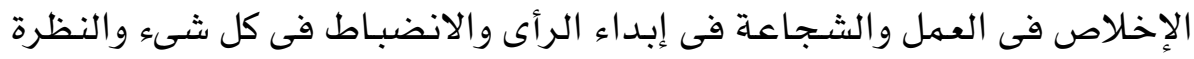
المتأنية فى الحكم على الأشياء والترفع عن الصغائر وعدم الانشغال بتوافه الأمور

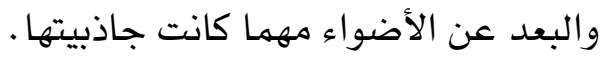


وقد تعلمت منه الكثير وأهم مـا تعلمته الحرص على مصلحة الوطن وإعلاء شأنه والتهسك بالثوابت والتواصل مع الآخرين لخدمة الإسـلام وتاريخه. حفظ -رحمها الله- القرآن الكريم حفظاً جيداً وكان يضـايقه كثيراً أن يرى

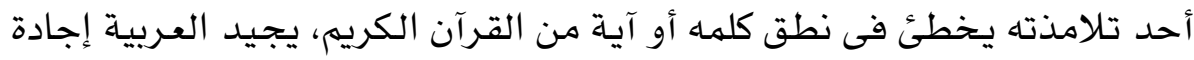
تامة ويكتب بها مؤلفاته بأسلوب متفرد لايضاهيه أحد حتى فى محاضر آنساته كان لا لا

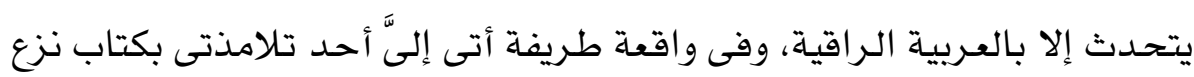

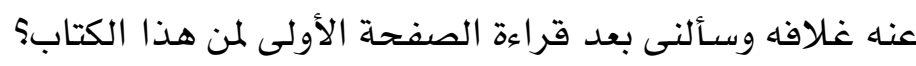
ودون تـردد وقبل أن أكمل الصـفــــة قلت أنه لــيـخــا وأسـتاذنـا الـدكتور

$$
\text { عبدالعزيز الشناوى وعنوان الكتاب هو: }
$$

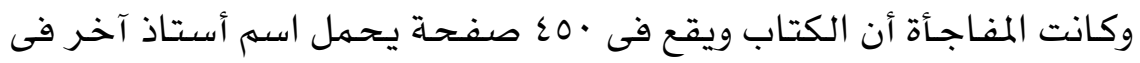

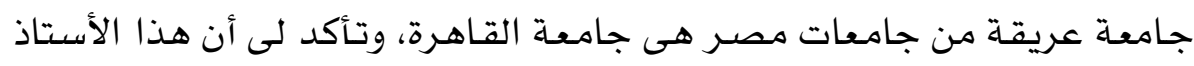

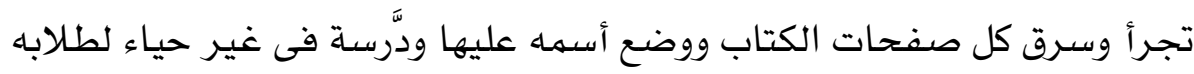

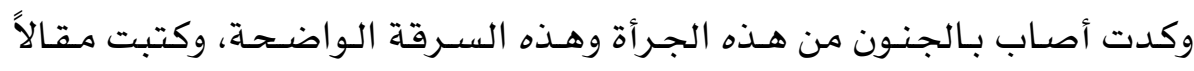

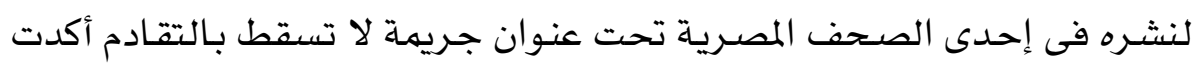

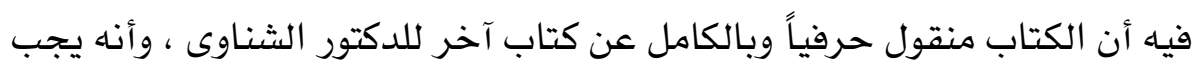

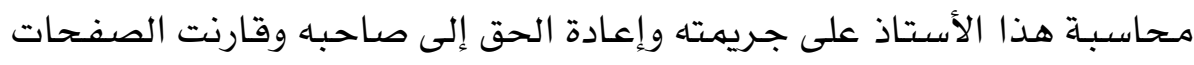

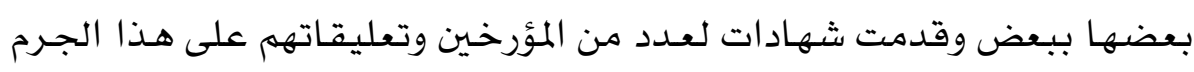

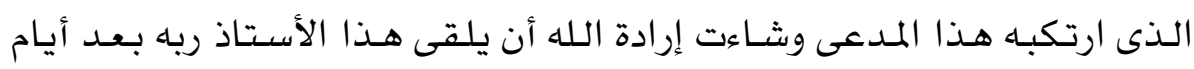

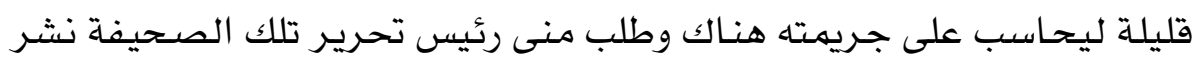

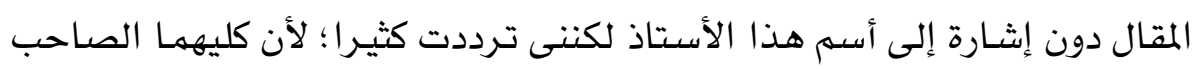

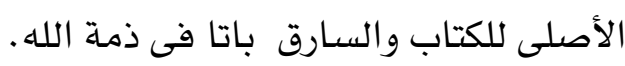

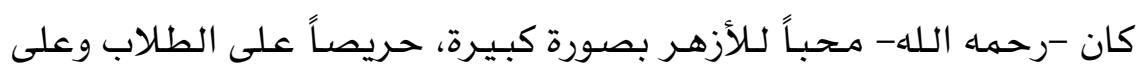

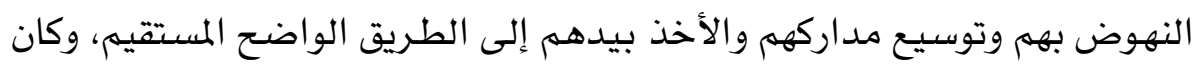

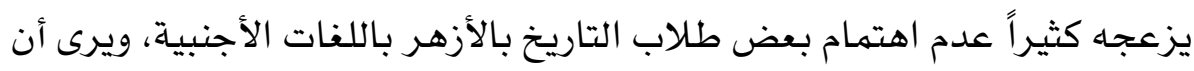


ذلك يهـثل نقطة ضعف واضـحـة، كمـا كان ينتقـــ عدم اهـتهـام معظظم الأزهـرين

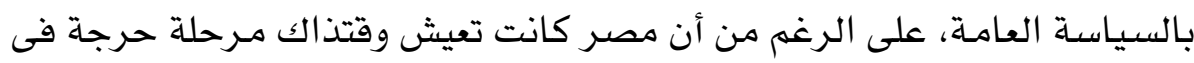
تاريخها الحديث.

تتلهــذ على يـدياه كثيـرون من مؤرخى الأزهـر وعلهمائه وعلى رأسـهـه الدكتور

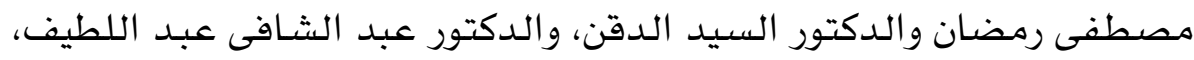

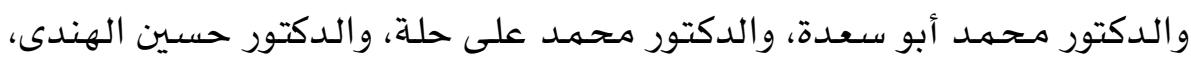
والدكتور محمد صابر عرب، وكاتب هذا المقال. أشـرف الدكتور الشنـاوى على مئـات الرسـائل فى جامعـة الإسـكندرية وعين

$$
\text { شمس والأزهر وناقش الكثير من الرسائل. }
$$

وآخر رسـالـة أشـرف عليها فى حياته كانت رسـالتى تحت عنوان: "العلاقات المصرية العثمانية فى عصر عباس الأول"، عاش - رحمـة الله- فى صست ومات كذلك وحيدا لم يشيعه إلى مثواه الأخير إلا محبوه وتلامذته والشىء المؤسف أن

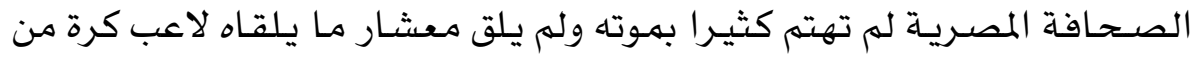

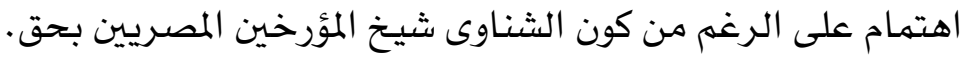
تنـاول الـدكتور الشنـاوى كتابة التـاريخ وتحليله بأسـلوب متفرد وحياد تام وموضوعية تظهر فى كل كلمة يكتبها . له يـتحـدث عن نـفساه، بل عكف فى صـمت ورهـبـانـيـة عـلى إخـراج روائعـاه وملفــاته "كالعقد الفريـد"، وآخر تلك الأعمال المتـميزة كانت موسـوعـة "الدولية العثمانيـة دولة إسـلاميـة مفترى عليها" التى قضى فى تأليفها أكثر من عشرين

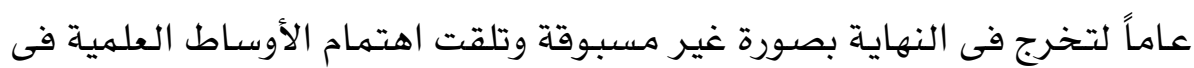
مصر والعالم العربى وصدر آخر جزء منها وهو الجزء الرابع بعد وفاته - رحمها الله- تحدث عن الدولة العثمانية لأول مرة فى الشرق العربى بحياد تام وانصاف

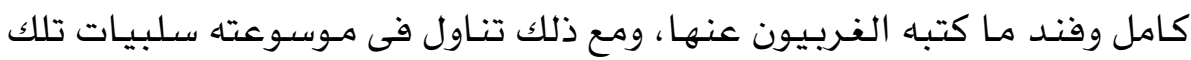


كما سـجل بفخر واعتزاز مـا قدمته للعـالميـن العربى والإسـلامى أخيـراً وبعد

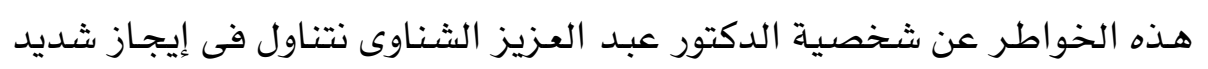

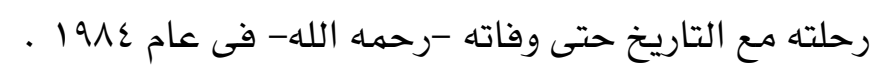
محنة الشناوى:

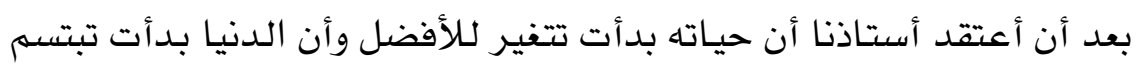

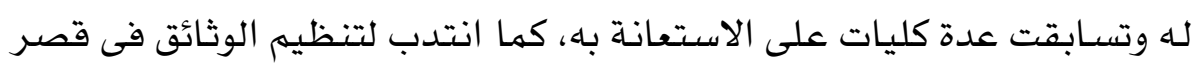

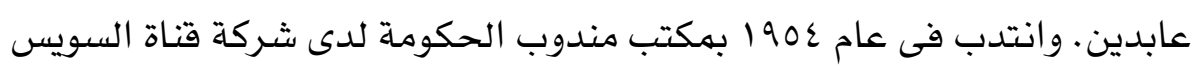

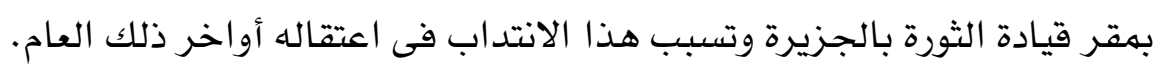
وقد وقع ذلك الاعتقـال عندما نسب إليه التسبب في فقدان إحدى الوثائق

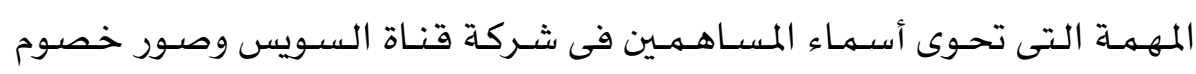

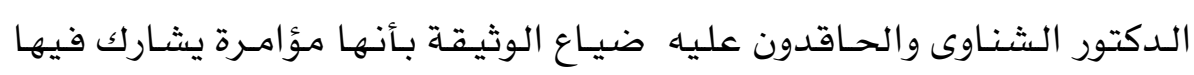

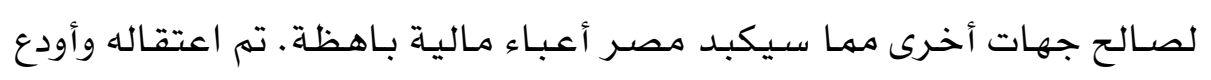

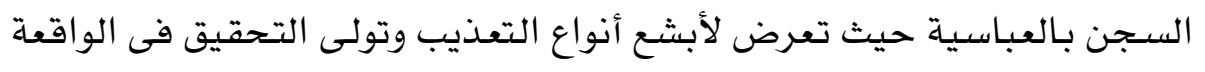

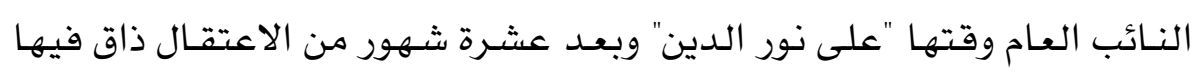

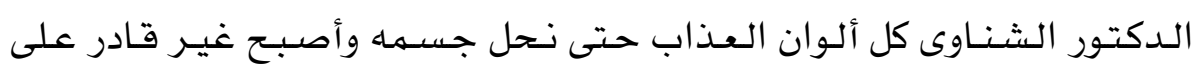

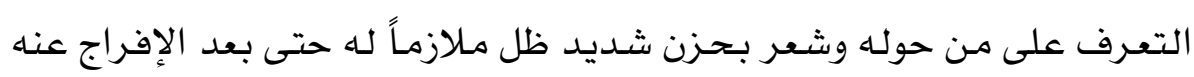
فهل يعقل أن يتعرض أستاذ جامعى كبير بحجم الدكتور الشناوى لكل هذه الأنواع

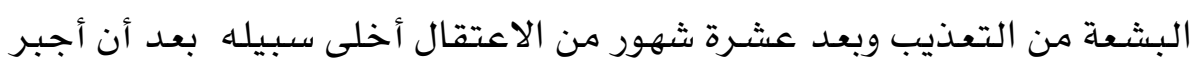
على التوقيع على تعهد بعدم المطالبة بالتعويض عن فترة اعتقاله أو حتى التلميح

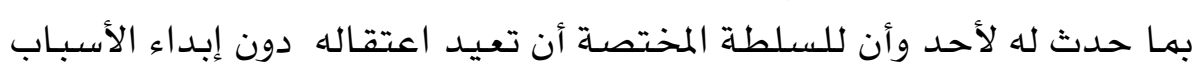

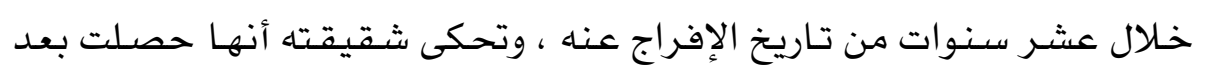

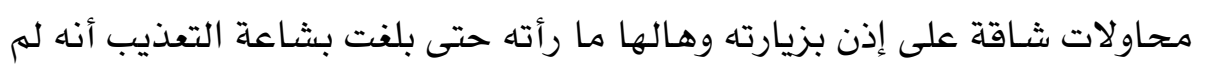
يتعرف عليها . ويحكى ابنه المستشار محمد الشنـاوى عن أسباب اعتقاله أنه سئل من قبل 
رئاســة الجمهوريـة قبل تأميهم قنـاة السويس عن الوثائق الخـاصـة بـالقناة والتى

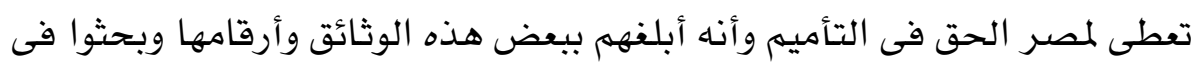

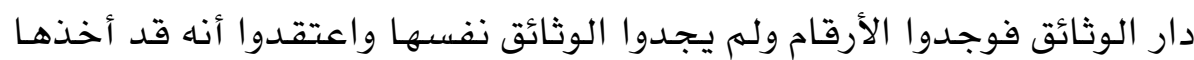

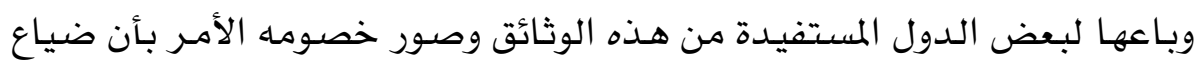

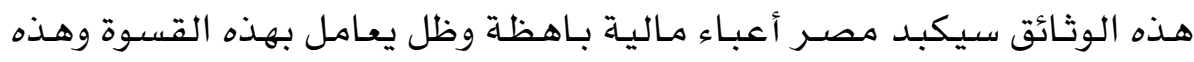

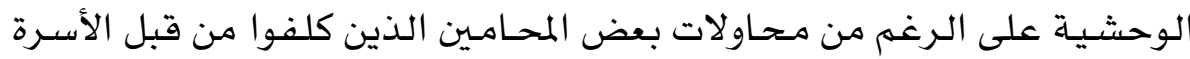

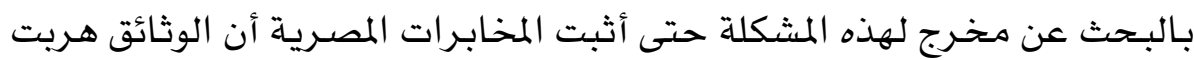

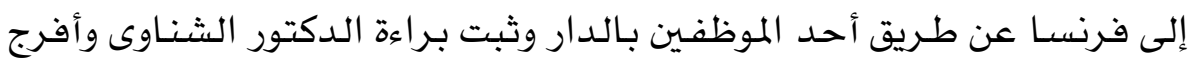

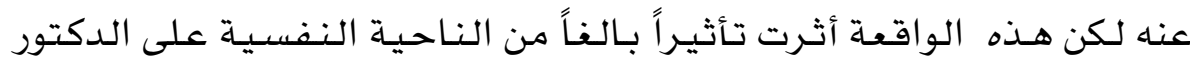
الشنـاوى حتى أنه كان يتحاشى الحـديث عنها وقد حاولت معرفة الحقيقة منها

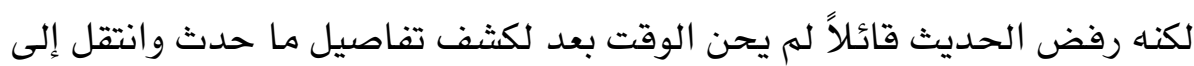

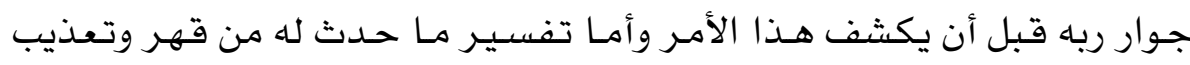

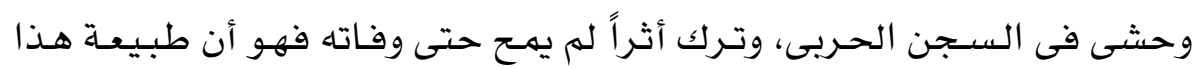

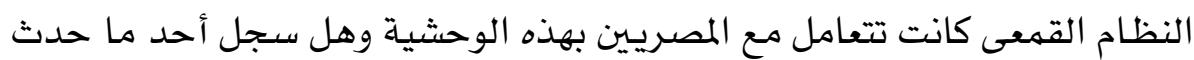

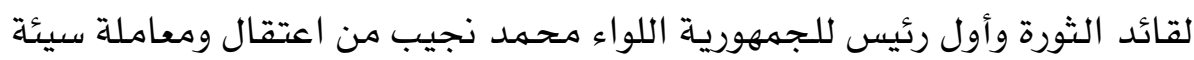

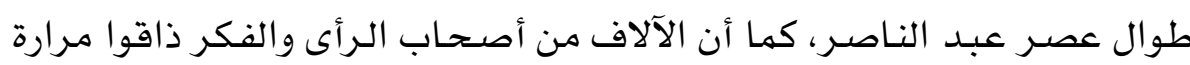
السجن، حتى قال البعض أن مصر كلها أصبحت سجناً كبيراً لأبنائها. والأهم أن نظرة الرئيس عبد النـاصر إلى أساتذة الجـامعات فى مصر كانت

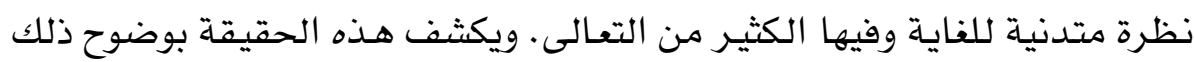

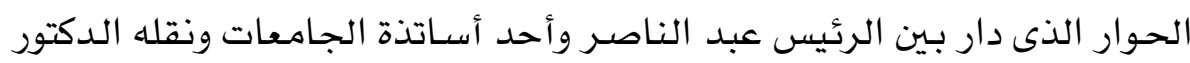

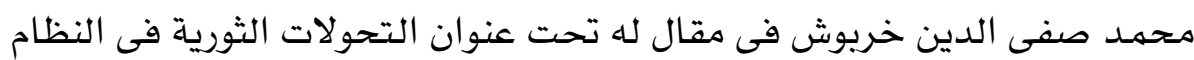
المصرى. ذكر عبد النـاصر فى كتابه "فلسفة الثورة ".. لقد كنت أتصور قبل بץ يوليو

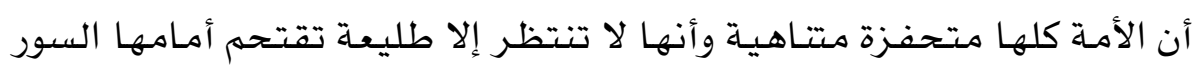


فتندفع الأمة وراءهـا صفوفاً متراصـة منتظمة تزحف زحفـا مقدساً إلى الهدف الكبير أظن أن دورنا هذا لا يستفرق أكثر من بضع ساعات ويأتى بعدها الزحف المقدس.

ثم فاجـأنى الواقع بعد با يوليو ـ كانت الجهموع التى جاءت أشياعاً متفرقة

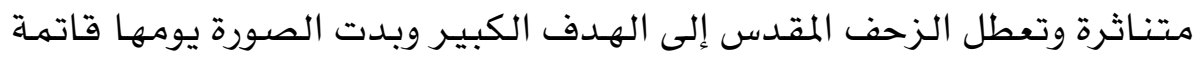
مخيفة تتذر بالخطر.

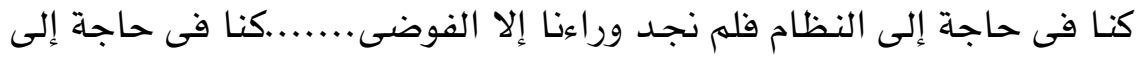
العمل فلهم نجـد إلا الخضـوع. أكثر من هـا رسهم الزعيم صورة أكثر قتامـة حسين

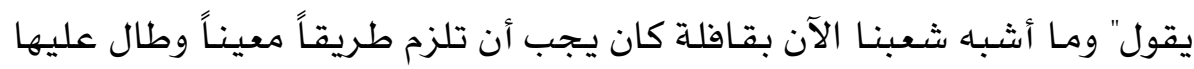
الطريق وقابلتها المصاعب وتعرض لها اللصوص وقطاع الطرق فتبعثرت القافلة كل جماعة فيها شردت فى مكان وكل فرد سار في اتجاه" . وفيما يتعلق بالحط من قيمـة النخبـة المثقفـة والإعلاء فى نفس الوقت من

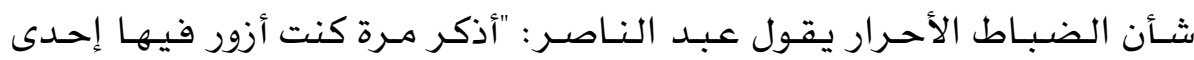

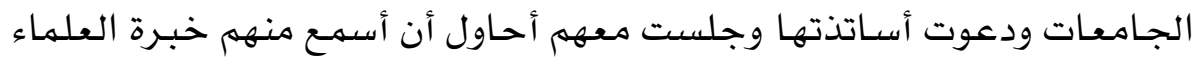

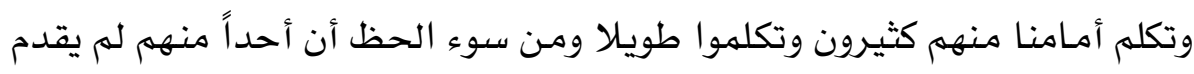

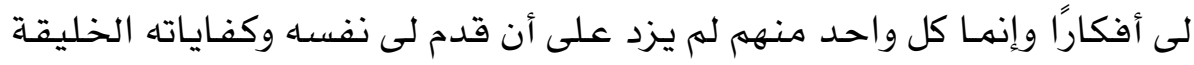
وحدها بعمل المعجزات ورمقنى كل واحد منهم بنظرة توحى أنه يؤثرنى على نفسهاه

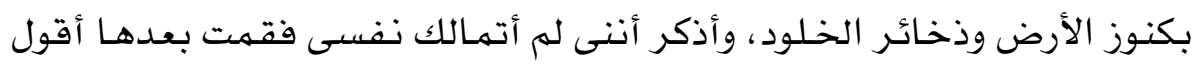

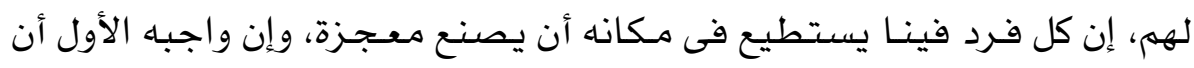

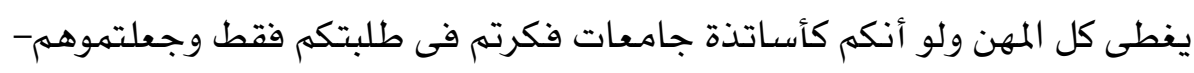

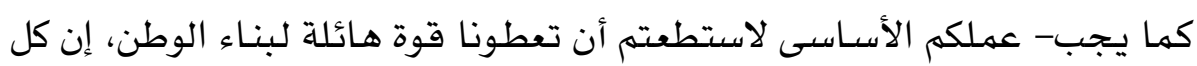

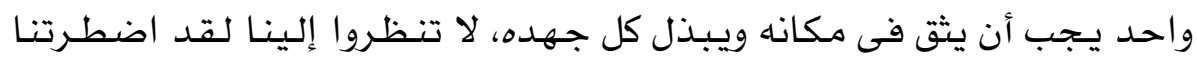
الظروف أن نخرج من أماكنتا لنقوم بواجب مقدس، ولقد ولند كنا نتمنى لو للم تكن للوطن حاجة بنا إلا فى صفوف الجيش كجنود محترفين وإذن لبقينا فيه. 
ولم أشـأ سـاعتها أن أضـرب لهم المثل من أعضاء مجلس قيادة الثورة ولهم أشـأ

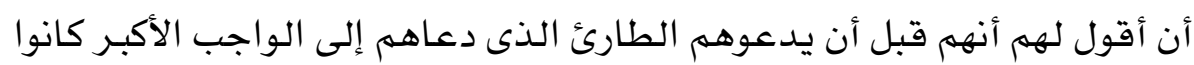

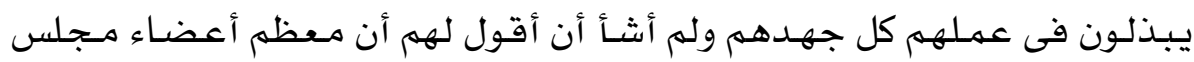
قيادة الثورة كانوا أسـاتذة فى كلية أركان الحرب وهذا دليل امتيازهم من ناحيتهم

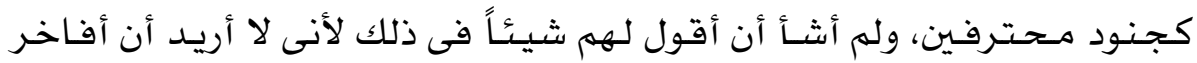
الناس بأعضاء مجلس قيادة الثورة وهـم اخوتى وزملائى. فالجماهير مترددة خائفة وفى حالية فوضى وهى عبـارة عن قافلة مبعثرة

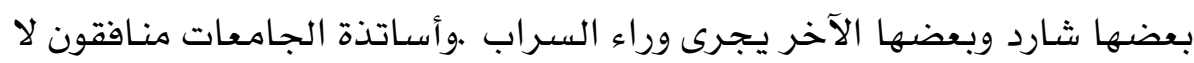

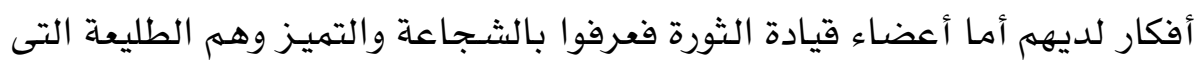
ستجمع الشاردين والتائهين وتضعهم على الطريق السليم". كانت تلك هى وجهة نظر عبـد النـاصـر إلى النتخبة وإلى أسـاتذة الجـامعات،

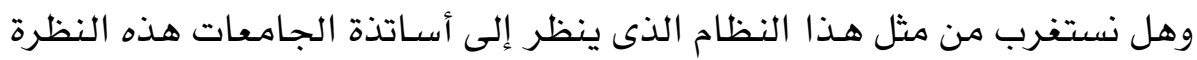

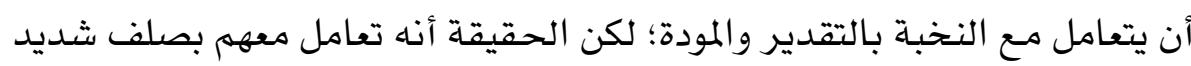

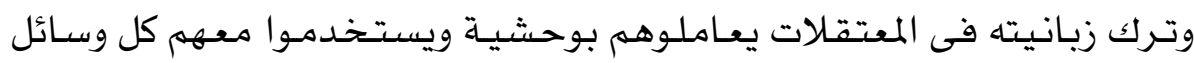

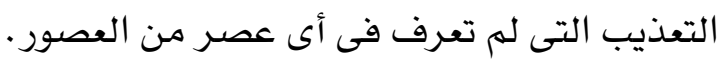

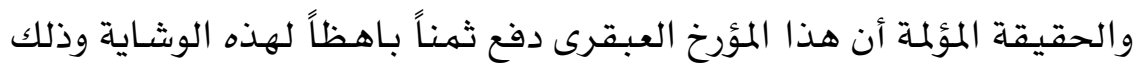

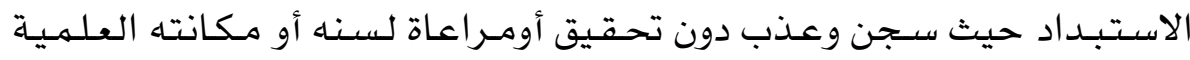




$$
\text { والأدبية. }
$$

ومن يقـرأ كتاب عبد النـاصر فلسفة الثورة يعرف جيداً كيف كان ضبـاط الحركة ينظرون إلى الجامعات وأسـاتذتها .

خاتمـة: على الرغم من المحنـة التى تعرض لها الشنـاوى إلا أنها بعد أن ظهرت براءته

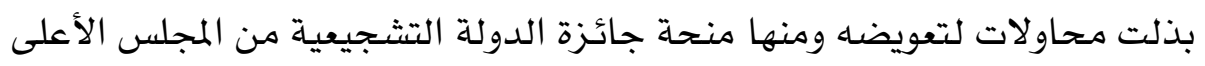
لرعاية الفنون والآداب والعلوم الاجتماع عام 19VY في عصر الرئيس الراحل أنور السادات.

كما منح فى عصر السادات كذلك وسـام العلوم والفنون من الطبقة الأولى فى

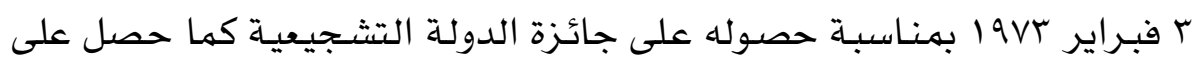

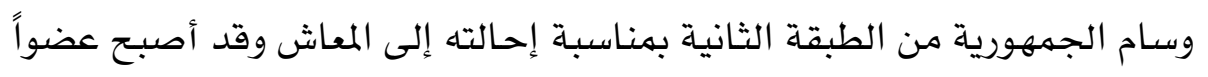

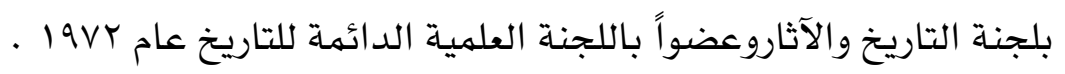
وفى عام •191 أصبح عضواً بالمجلس الأعلى للشئون الإسـلامية. وأمـا عن أعماله ومؤلفاته فمن الصعوبة تتاولها فى مقالة بهذا الحجم ولكن

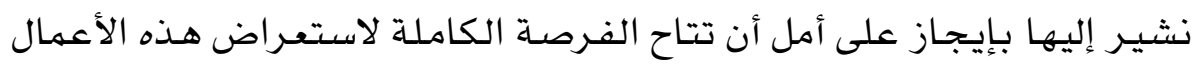

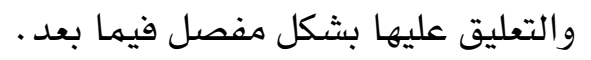
وهو كما يقول المؤرخ الراحل عبد العظيم رمضـان من المؤرخين العظام الذين

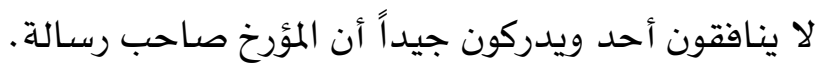
ومن أشهر أعمال المؤرخ الراحل الدكتور الشناوى: - "السخرة فى حفر قناة السويس:" - "وثائق ونصوص فى التاريخ الحدث والمعاصر" - "أوربا فى مطلع العصور الحديثة" 


$$
\begin{aligned}
& \text { - "عمر مكرم" فى سلسلة اعلام العرب } \\
& \text { - "دراسـات فى تاريخ مصر الحديث" } \\
& \text { - "تاريخ أوريا فى القرن التاسع عشر" }
\end{aligned}
$$

- "قناة السويس والتيارات السياسية التى أحاطت بها"

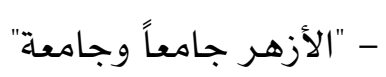

$$
\text { - "دور الأزهر فى الحفاظ على الطابع العربى لمصر" }
$$

وآخر أعماله وإنجازاته موسوعته التى لم تكتمل وصدر الجزء الرابع منها بعد

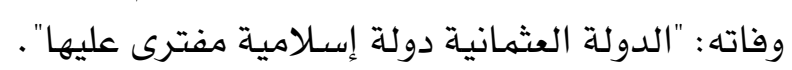

وقد عكف فى صست ورهبانية على كتابة تلك الموسوعة حتى أخذت منه أكثر

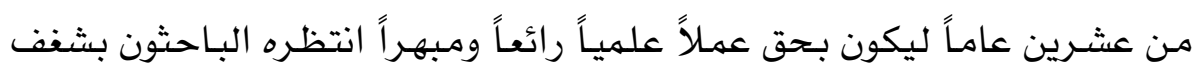

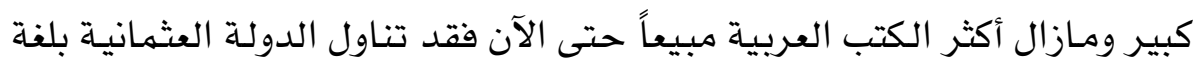
راقيـة وتحليل واف له يترك شـارده ولا وارده إلا أتى بها،وناقش مانش ما كتبه المؤرخون الغربيون عنها باستفاضه . روليه

وقد لقى الدكتور الشناوى ربه راضيا مرضيا فى يوليو 1917 بعد حياة حافلة

$$
\text { مليئة بالإنجازات جعلته واحدا من كبار المؤرخين المعاصرين. }
$$

وأخيراً اعتذر لقراء تلك المجلة الراقية المتخصصة عن هذا الإيجاز فالدكتور

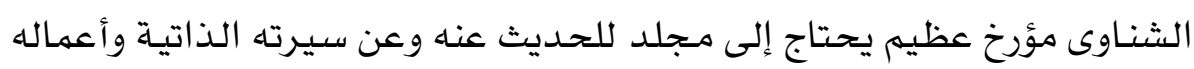
الكثيرة لكن كما يقال مالا يدرك كله لا يترك كله لهونه

رحمها الله رحمـة واسعة وجزاه خيراً عما قدم للمكتبة العربية من نفائس بلغة لهاه وأسلوب لا نظير له بين المؤرخين القدامى والمحدثين.

$$
\text { أسـانيد المقال }
$$

- السعيد رزق حجاج: خواطر وحوارات مع الدكتور الشناوى فى حياته. 
- السعيد رزق حجـاج: مقدمة رسـالة الدكتوراه التى أشـرف عليها الدكتور

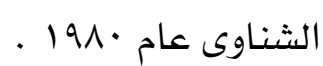

- الزعيم جمال عبد الناصر : فلسفة الثورة. القاهرة الدار القومية للطباعة

$$
\text { والنشر . }
$$

- صفى الدين خريوش: التحـولات الثورية مـن مقال ضـمن أعمال المؤتمـر

السنوى للبحوث السياسية تحت عنوان النظام السياسى المصرى جامعة القاهرة-

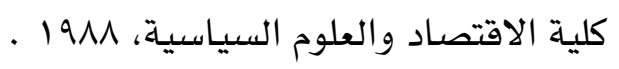

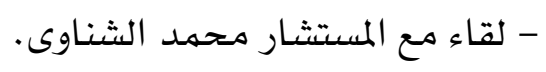

- بعض مؤلفات الدكتور الشناوى ومنها : السخرة فى حفر قناة السويس طبعة

- أوربا فى مطلع العصور الحديثة، 1979 ـ .

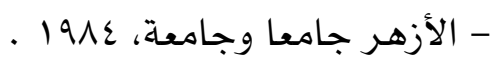

- عمر مكرم بطل المقاومة الشعبية، 1978 -

- الدولة العثمانية دولة إسـلامية مفترى عليها فى أربعـة أجزاء صدر أخرها

$$
\text { في } 1917 .
$$

- بعض المحاضرات الخاصة للدكتور الشناوى.

- مقدمة كتاب د. حسن صبرى الخولى: سياسة الاستعمار والصهيونية- فى

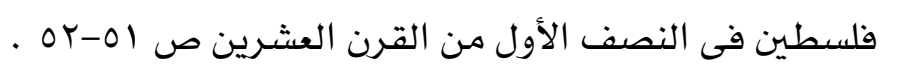

- بهاء علوان: الشناوى مؤرخا.

- دـ ـ عبد العظيه رمضان مقال عن الشناوى فى مجلة أكتوبر، 191V . - حديث خاص مع المؤرخ الراحل الدكتور جلال يحيى. 